\title{
A Specific, Sensitive Method for the Determination of Hyaluronate ${ }^{1}$
}

\author{
George W. Jourdian, Melinda Wolfman, Robert Sarber, ${ }^{2}$ and Jack Distler \\ Rackham Arthritis Research Unit, and the Departments of Biological Chemistry and Internal Medicine. \\ The University of Michigan Medical Schoal, Ann Arbor, Michigan 48109
}

Received November 29, 1978

\begin{abstract}
A sensitive and specific assay for hyaluronate was devised. Hyaluronate contained in biological mixtures was digested with a commercially available microbial hyaluronate lyasc. The $\beta$ - $\Delta 4,5$-eneglucopyranuronic acid residues contained at the nonreducing termini of the resulting oligosaccharides were oxidized with periodic acid to yield, among other products, formyl pyruvic acid. The latter compound reacted with thiobarbituric acid to yield a chromophore with an absorption maximum at $549 \mathrm{~nm}$. Optimal conditions for quantitative assay of hyaluronate are described.
\end{abstract}

At present there is no simple method for the rapid and specific detection and quantitation of microamounts of hyaluronate. Classically, the concentrations of hyaluronate in biological solutions have been determined by turbidimetric methods (1), or by quantitative determination of its constituents after acid hydrolysis (2). However, these procedures are not specific for the determination of hyaluronate. Other methods depend upon isolation and chemical characterization and involve ion-exchange chromatography (3), cetylpyridinium chloride-cellulose microcolumns $(4,5)$, and cellulose acetate electrophoresis (6). While generally satisfactory, these methods are time-consuming and are compromised if a large excess of other glycosaminoglycans are present in the sample. A highly sensitive and specific proteoglycan-binding assay for hyaluronate contained in mixtures of glycosaminoglycans has been reported but requires prior isolation of cartilage proteo-

\footnotetext{
1 This work was supported by Grant HL 19685 from the National Institute of Heart and Lung Diseases, National Institutes of Health, and in part by the Arthritis Foundation, Michigan Chapter.

${ }^{2}$ Postdoctoral trainee, Training Grant AM 07080 from the National Institute of Arthritis, Metabolic and Digestive Diseases, National Institutes of Health.
}

glycans by density gradient centrifugation, column chromatography on agarose, and determination of the proteoglycan-hyaluronate complex elution profile by measurement of uronic acid concentration (7).

An alternative approach, utilized by a number of investigators for the determination of hyaluronate, has been the application of microbial hyaluronate lyases. In contrast to animal hyaluronidases (hyaluronate glycanohydrolase EC 3.2.1.35), the microbial hyaluronate lyases (hyaluronate lyase EC 4.2.2.1) are eliminases and hydrolyze hyaluronate to oligosaccharides containing terminal $\Delta 4,5$-unsaturated glucopyranuronic acid $^{3}$ units (8); the unsaturated compounds have a characteristic absorption maximum at $232 \mathrm{~nm}$. This property served as the basis for the development of direct spectrophotometric means for the measurement of hyaluronate. However, biological fluids and tissue extracts usually contain high levels of ultraviolet-absorbing compounds such as protein and nucleic acids which interfere with the quantitative measurement of the $\Delta 4,5$-unsaturated uronic acid residues by

\footnotetext{
${ }^{3} \Delta 4,5$-Unsaturated glucopyranuronic acid oligosaccharides $=(3-O-\beta-\Delta 4,5$-ene- $\mathrm{D}$-glucopyranuronic acid-2-acetamido-2-deoxy-D-glucose $)_{n}$.
} 
this methodology (9). The latter problem has in part been circumvented by colorimetric measurement of liberated $N$-acetylglucosamine end groups by a modification of the Morgan-Elson reaction (10). However, crude tissue extracts produce spurious color and the colorimetric determination is affected by the presence of even moderate protein concentrations (2). The enzymatic determination of hyaluronate in biological fluids is further limited by the observation that heparin, chondroitin 4-sulfate, and dermatan sulfate competitively inhibit some hyaluronate lyases (2). Ohya and Kaneko (11) have isolated a novel hyaluronate lyase from Streptomyces hyalurolyticus which is reported not to be inhibited by glycosaminoglycans. The enzyme is specific for hyaluronate, catalyzes the formation of oligosaccharides terminating in $\Delta 4,5$-unsaturated glucuronic acid units, and is stable at elevated temperatures.

Hascall et al. (12) observed that a periodate-thiobarbituric acid reagent reacted with $\Delta 4,5$-unsaturated uronic acid-terminating oligosaccharide chains (found on treatment of bovine nasal cartilage proteoglycan with microbial chondroitinases) to yield a chromophore with an absorption at $549 \mathrm{~nm}$. This observation served as the basis for development of a convenient assay for the degradation of bovine nasal proteoglycan by chondroitinase $\mathrm{ABC}$ and $\mathrm{AC}$ activities. Koseki et al . (13) applied a similar periodatethiobarbituric acid assay procedure, described by Warren (14), to the microdetermination of chondroitin 4- and 6-sulfate and dermatan sulfate after prior digestion with microbial chondroitinases.

The above observations served as the basis for development of a specific and sensitive enzymatic-colorimetric assay for hyaluronate described in this manuscript.

\section{MATERIALS}

Glycosaminoglycans. The following glycosaminoglycans served as reference standards and were generous gifts of Dr. M. B. Mathews, University of Chicago: hyaluronate (human umbilical cord), chondroitin 4-sulfate (sturgeon cranial cartilage), chondroitin 6-sulfate (sturgeon notochord), dermatan sulfate (hog mucosa), keratan sulfate (bovine cornea), and heparin and heparan sulfate (beef lung). Hyaluronate was also prepared from human synovial fluid by electrodeposition (15). Chondroitin was prepared from chondroitin 4-sulfate by solvolytic desulfation with dimethyl sulfoxide (16).

Hyaluronate lyase. Hyaluronate lyase purified from Streptomyces hyalurolyticus (specific activity 3000 turbidity reducing units (TRU) $/ \mathrm{mg}$ protein) ${ }^{4}$ was obtained from Calbiochem.

Reagents. The following compounds were obtained from the indicated sources: sodium periodate and $n$-butyl alcohol, J. T. Baker Chemical Company; sodium arsenite and $p$-dimethylaminobenzaldehyde, Baker and Adamson; ammonium dihydrogen orthophosphate, BDH Chemicals Ltd.; and thiobarbituric acid, Eastman Chemical Company. All other reagents were of analytical grade or of the highest purity commercially available. Dialysis tubing with a molecular weight cutoff of 3500 was purchased from Arthur H. Thomas Company.

\section{METHODS}

\section{Standard Assay Procedure}

Incubation with hyaluronate lyase. Reactions were performed in $15 \times 125$-mm Pyrex tubes. Enzymatic digestions contained the following components in a total volume of $0.2 \mathrm{ml}$ : sodium acetate buffer, $\mathrm{pH} 5.0,4.0$ $\mu \mathrm{mol} ; 1.66 \mu \mathrm{g}$ hyaluronate lyase (5 TRU); and 0 to $100 \mu \mathrm{g}$ of sodium hyaluronate. Control tubes contained the same components but lacked either substrate or enzyme. The reaction mixtures were incubated at

\footnotetext{
* Enzyme activity is expressed in turbidity units (TRU) as defined by Tolksdorf et al. (17).
} 
$60^{\circ} \mathrm{C}$ for $5 \mathrm{~h}$ and enzyme action was terminated by the addition of $0.25 \mathrm{ml}$ of $0.04 \mathrm{M}$ $\mathrm{NaIO}_{4}$ contained in $0.08 \mathrm{~N} \mathrm{H}_{2} \mathrm{SO}_{4}$.

Measurement of eliminase products. The conditions used were similar to those described by Hascall et al. (12). After addition of the periodate $-\mathrm{H}_{2} \mathrm{SO}_{4}$ reagent the reactants were mixed and the tubes placed in a $37^{\circ} \mathrm{C}$ water bath for $1 \mathrm{~h}$ to allow oxidation to proceed. Excess periodate was destroyed by addition of $0.5 \mathrm{ml}$ of $3 \%(\mathrm{w} / \mathrm{v})$ $\mathrm{NaAsO}_{2}$ contained in $0.5 \mathrm{~N} \mathrm{HCl}$. The reactants were mixed, allowed to stand at room temperature for $30 \mathrm{~min}$, and $4 \mathrm{ml}$ of $0.3 \%$ thiobarbituric acid contained in $0.012 \mathrm{~N}$ $\mathrm{HCl}$ were added to each tube. The contents were again mixed thoroughly and the tubes capped with marbles, heated at $100^{\circ} \mathrm{C}$ for $15 \mathrm{~min}$, and cooled to room temperature. In contrast to the procedure of Hascall et al. (12) we routinely extracted the chromophore with $4 \mathrm{ml}$ of $5 \% \mathrm{HCl}$ in $n$-butyl alcohol to enhance the sensitivity of the assay procedure. Absorbance of the butanol layer was determined at $549 \mathrm{~nm}$.

\section{RESULTS AND DISCUSSION}

\section{Enzyme Incubation Conditions}

Ohya and Kaneko (11) previously established that Streptomyces hyaluronate lyase is stable over a wide $\mathrm{pH}$ and temperature range; the presently described assay procedure was conducted at the established $\mathrm{pH}$ and temperature optima, $\mathrm{pH} 5.0$ and $60^{\circ} \mathrm{C}$, respectively. Routinely, the enzyme was dissolved in $0.04 \mathrm{M}$ sodium acetate buffer, $\mathrm{pH} 5$, at a level of $200 \mathrm{TRU} / \mathrm{ml}$. No appreciable loss in activity (less than $5 \%$ ) was observed on storage of the diluted enzyme at $-19^{\circ} \mathrm{C}$ for 1 month.

In the standard assay procedure the sample is incubated with hyaluronate lyase for a period of 5 h. As shown in Fig. 1, this time of incubation resulted in complete product formation over the concentration range of hyaluronate employed. Maximal product formation was achieved with 5 TRU of

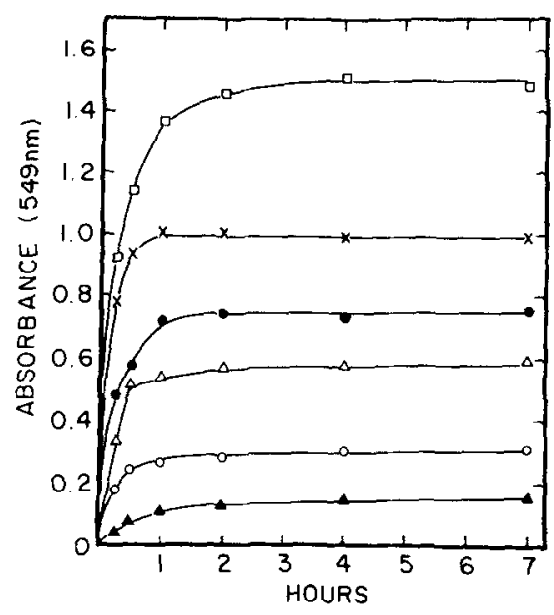

FIG. 1. The formation of periodate-thiobarbituric acid reactive compounds from hyaluronate as a function of time of incubation with Streptomyces hyaluronate lyase: effect of substrate concentration. The incubation conditions were those described for the standard assay procedure except the hyaluronate concentrations (expressed in $\mu$ g/incubation) were as follows: (A) 10, (O) 20, ( $\triangle$ ) 35, (O) 50, (X) 75, and (口) 100 .

hyaluronate lyase in each incubation. Lower amounts of hyaluronate lyase, i.e., less than 3 TRU per incubation, resulted in significantly lower initial rates and decreased product formation (Fig. 2). Variation of absorbance values on a day-to-day basis using the same standard hyaluronate solution was within $\pm 5 \%$.

\section{Enzyme Specificity}

Ohya and Kaneko (11) reported that Streptomyces hyaluronate lyase specifically catalyzes the hydrolysis of hyaluronate and, in contrast to other microbial hyaluronate lyases, is not inhibited by other glycosaminoglycans. In vicw of the importance of these considerations for the specific determination of hyaluronate in biological samples, we reexamined the substrate specificity of Streptomyces hyaluronate lyase and the ability of other glycosaminoglycans to inhibit Streptomyces hyaluronate lyase. The following glycosaminoglycans were studied: chondroitin 4- and 6-sulfate, chon- 


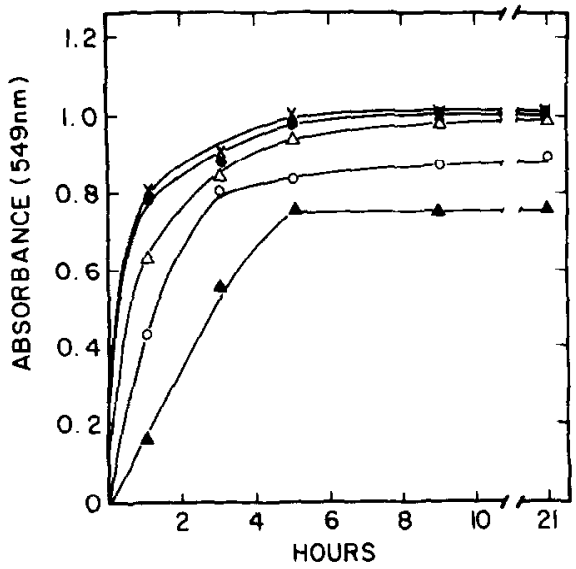

F1G. 2. The formation of periodate-thiobarbituric acid-reactive compounds from hyaluronate as a function of time of incubation with Streptomyces hyaluronate lyase; effect of enzyme concentration. The incubation conditions were those described for the standard assay except the hyaluronate lyase concentrations (expressed in TRU/incubation) were as follows: (A) $1,(\bigcirc) 2,(\triangle) 3$, (O) 4, and $(X) 5$.

droitin, dermatan sulfate, heparin, heparan sulfate, and keratan sulfate. The standard assay conditions were employed. For specificity studies $50 \mu \mathrm{g}$ of a single glycosaminoglycan was added to a reaction mixture as a substrate and for inhibition studies each reaction mixture contained $50 \mu \mathrm{g}$ of hyaluronate and $500 \mu \mathrm{g}$ of another glycosaminoglycan. In agreement with the findings of Ohya and Kaneko no absorbance over the blank value was obtained with any glycosaminoglycan other than hyaluronate. Furthermore, the absorbance obtained from hyaluronate was not altered when the other glycosaminoglycans were present during the incubation.

\section{Factors That Affect Periodate- Thiobarbituric Assay}

As shown in Fig. 3, the sensitivity of the colorimetric procedure described by Hascall et al. (12) was enhanced approximately 2.5 times by extraction of the chromophore into acidified $n$-butyl alcohol, a method previously described by Aminoff for enhancement of the sensitivity of the same chromophore derived from sialic acid (18). Unextracted and $n$-butyl alcohol-extracted samples lost less than $8 \%$ of their color in $6 \mathrm{~h}$ and under the assay conditions described, the formation of $n$-butyl alcohol-extractable chromophore was linear with hyaluronate concentrations between 5 and $100 \mu \mathrm{g}$ per reaction mixture.

While the current studies were in progress, a micromethod for the determination of chondroitin 4- and 6-sulfate and dermatan sulfate, after prior digestion with chondroitinase $\mathrm{ABC}$ and $\mathrm{AC}$, was reported by Koseki et al. (13). The methodology applied a modification of the periodate-thiobarbituric acid method of Warren (14) to the assay of $\Delta 4,5$-unsaturated uronic acid-containing disaccharides derived from these glycosaminoglycans. The authors reported their assay procedure was approximately threefold more sensitive than that described by Hascall et al. (12). When the periodatethiobarbituric acid conditions of the Japanese investigators were applied to the determination of hyaluronate (using the incubation conditions described in the pres-

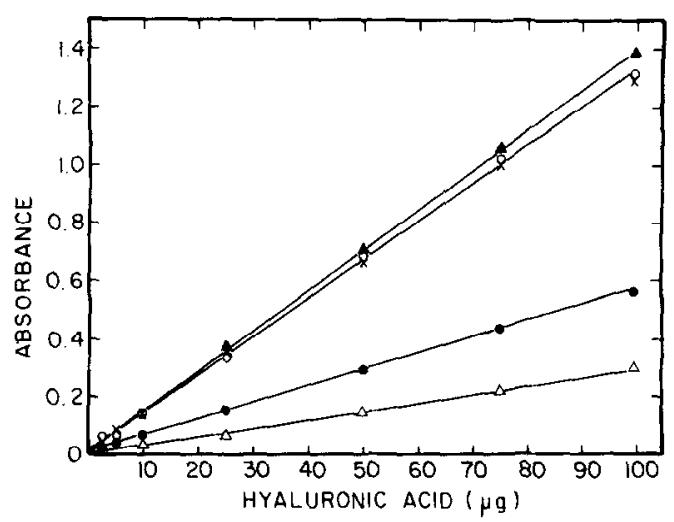

Fig. 3. Determination of the absorbance (color yield) generated by $\Delta 4,5$-unsaturated glucopyranuronic acid-containing oligosaccharides in Streptomyces hyaluronate lyase digests of hyaluronate by the following colorimetric and spectrophotometric procedures: $(\triangle)$ absorption at $232 \mathrm{~nm}(8)$; (O) $549 \mathrm{~nm}$, Hascall et al. (12); (X) Koseki et al. (13); (O) 549 nm, determined by the methodology described in this manuscript; and (A) $585 \mathrm{~nm}$, Morgan-Elson reagent as modified by Reissig et al. (10). 
ent manuscript), less than a $1 \%$ difference in color yield was observed from that obtained by the presently described methodology (Fig. 3). In our experience, the pracedure described originally by Hascall et al. (12) coupled with extraction of the chromophore with acidified $n$-butyl alcohol is technically easier, is less time-consuming, and requires fewer reagents than the procedure of Koseki et al. (13).

The absorbance values obtained at several hyaluronate concentrations with the modified Morgan-Elson procedure of Reissig et al. (10) and direct spectrophotometric estimation at $232 \mathrm{~nm}$ are also presented in Fig. 3. Nearly equivalent absorbance values were obtained with the Morgan-Elson and the periodate-thiobarbituric acid procedures at equivalent hyaluronate concentrations; the absorbance values obtained by direct measurement of the unsaturated products at $232 \mathrm{~nm}$ were approximately fivefold lower than those obtained by the periodate-thiobarbituric acid or MorganElson procedures.

\section{Assay of Hyaluronate in Biological Fluids and Extracts}

Accurate measurement in crude biological preparations of products arising from the enzymatic degradation of hyaluronate by direct spectrophotometric measurement or by the Morgan-Elson procedure is restricted for the reasons cited in the introduction. The previous successful application of the periodate-thiobarbituric acid reagents to the determination of free sialic acid in crude biological mixtures sugggested that the unsaturated oligosaccharides derived from hyaluronate could also be measured in such mixtures. While the presently described methodology has not been extended to a large number of tissues, we are reporting its application to the determination of hyaluronate in lung extracts, as an example of a tissue which contains interfering substances, and in synovial tissue, where the presence of hyaluronate is well documented and can be determined by classical methods. Extracts of the soft tissue of lung are rich in compounds that have the potential to contribute to elevated blank values. These compounds include sialic acid-containing glycoproteins $(14,18)$, deoxyribose-containing nucleic acids (19), and lipids (20).

Neuraminidases present in lung extracts were found to release large amounts of free sialic acid from sialic acid-containing lung glycoproteins. Interference attributable to periodate oxidation of free sialic acid was avoided by dialyzing the extract to remove free sialic acid followed by heating at $100^{\circ} \mathrm{C}$ for $3 \mathrm{~min}$ to inactivate neuraminidase. As shown in Table 1, this heating step produced tolerable blank values with the lung extracts. The results presented in Table 1 also show that hyaluronate was not detected in lung extracts (less than $5 \mu \mathrm{g}$ / $100 \mu \mathrm{l})$. Analysis of the pooled lung extract for uronic acid (after papain digestion by the procedure of Schiller et al. (3)) showed it contained $0.24 \mu \mathrm{mol}$ uronic acid $/ 100 \mu \mathrm{l}$ extract. However, results described in Table 1 show that hyaluronate was not detected by the coupled enzyme-colorimetric procedure. These results suggest that in our lung preparation, hyaluronate contributes to less than $6 \%$ of total uronic acid. This is surprising in view of the reported prevalence of hyaluronate in lung tissue (22) and at present, no explanation can be offered for this apparent contradiction. When exogenous hyaluronate was added to lung extracts prior to heating, more than $95 \%$ was recovered by the coupled enzymecolorimetric procedure (Table 1).

The residual color noted in the blanks from lung extracts has an absorption maximum at $532 \mathrm{~nm}$ and may arise from periodate oxidation of deoxyribose or unsaturated lipids. Oxidation of these compounds gives malonaldehyde which in turn reacts with thiobarbituric acid to give a colored complex with an absorption maximum at $532 \mathrm{~nm}$. The concentration of this chromophore 
TABLE 1

Assay of Hyaluronate in Lung Extract by a Streptomyces Hyaluronate Lyase-Periodate-Thiobarbituric Acid Procedure

\begin{tabular}{|c|c|c|c|c|}
\hline \multirow[b]{2}{*}{$\begin{array}{l}\text { Lung extract } \\
\qquad(\mu \mathrm{l})\end{array}$} & \multirow{2}{*}{$\begin{array}{l}\text { Hyaluronate } \\
\text { added } \\
(\mu \mathrm{g})\end{array}$} & \multicolumn{2}{|c|}{ Absorbancy $(549 \mathrm{~nm})^{\circ}$} & \multirow{2}{*}{$\begin{array}{l}\text { Hyaluronate } \\
\text { found } \\
(\mu \mathrm{g})\end{array}$} \\
\hline & & $\begin{array}{c}\text { Without hyaluronate } \\
\text { lyase }\end{array}$ & $\begin{array}{c}\text { With } 5 \text { TRU } \\
\text { hyaluronate lyase }\end{array}$ & \\
\hline \multicolumn{5}{|c|}{ Heating step omitted } \\
\hline 100 & & 0.545 & 0.520 & 0 \\
\hline \multicolumn{5}{|l|}{$\begin{array}{l}\text { Heated at } 100^{\circ} \mathrm{C} \\
\text { for } 3 \mathrm{~min}\end{array}$} \\
\hline 100 & & 0.072 & 0.077 & 0 \\
\hline 100 & 5 & 0.078 & 0.142 & 6.5 \\
\hline 100 & 25 & 0.069 & 0.344 & 27.0 \\
\hline 100 & 50 & 0.065 & 0.636 & 55.5 \\
\hline 100 & 100 & 0.069 & 1.056 & 95.8 \\
\hline
\end{tabular}

a Soft tissue was scraped from six freshly excised, perfused guinea pig lungs. The tissue ( $3.7 \mathrm{~g}$ ) was ground in a motor-driven Tefion-glass homogenizer with $10 \mathrm{ml} 0.1 \mathrm{M}$ sodium phosphate buffer, $\mathrm{pH}$ 6.0. The homogenate (20 mg protein $/ \mathrm{ml}$ ) was dialyzed at $4^{\circ} \mathrm{C}$ for $4 \mathrm{~h}$ against the buffer used for homogenization and $100-\mu \mathrm{l}$ aliquots (with or without added hyaluronate) heated at $100^{\circ} \mathrm{C}$ for $3 \mathrm{~min}$.

${ }^{b}$ Samples were treated with hyaluronate lyase and assayed by the periodate-thiobarbituric acid procedure as described under Methods.

obtained from lung extracts was not significantly reduced by prior extraction with 2 vol of chloroform-methanol (2:1). The residual blank value may therefore arise from the presence of deoxyribonucleic acid.

Synovial fluid is a rich source of hyaluronate (15). Analysis of a limited number of synovial fluid samples for hyaluronate by the coupled enzyme-colorimetric procedure (Table 2) yielded values similar but not identical to those obtained from computations based on uronic acid content. These tissues gave negligible blank values without the heating and dialysis steps that were required for analysis of the lung extracts. Analysis of two samples of synovial fluid

TABLE 2

Assay of Hyaluronate in Synovial Fluid by a Streptomyces Hyaluronate Lyase-Periodate-Thiobarbituric Acid Procedure

\begin{tabular}{lccccc}
\hline $\begin{array}{c}\text { Synovial } \\
\text { fluid }^{a}\end{array}$ & Diagnosis $^{b}$ & $\begin{array}{c}\text { Absorbancy at } 549 \mathrm{~nm}^{c} \\
\text { hyaluronate lyase }\end{array}$ & $\begin{array}{c}\text { With } 5 \mathrm{TRU} \\
\text { hyaluronate lyase }\end{array}$ & $\begin{array}{c}\text { Hyaluronate } \\
\text { found } \\
(\mathrm{mg} / \mathrm{ml})\end{array}$ & $\begin{array}{c}\text { Uronic acid } \\
\text { found }^{d} \\
(\mu \mathrm{mol} / \mathrm{ml})\end{array}$ \\
\hline S.Y. & RA & 0.025 & 0.116 & 0.37 & 1.6 \\
M.W. & RA & 0.016 & 0.535 & 2.02 & 7.8 \\
L.C. & SLE & 0.016 & 1.183 & 3.92 & 9.8 \\
\hline
\end{tabular}

${ }^{a}$ Individual synovial fluid samples were received from the clinical laboratory of the Arthritis Division and were obtained as by-products of routine diagnostic procedures.

${ }^{b}$ RA, rheumatoid arthritis; SLE, systemic lupus erythematosus.

${ }^{c}$ Aliquots of the synovial fluids $(25 \mu l)$ were treated with hyaluronate lyase and assayed by the periodatethiobarbituric acid procedure as described under Methods.

${ }^{d}$ Uronic acid analyses were performed by the procedure of Bitter and Muir (21). 
from rheumatoid arthritis patients indicated that hyaluronate accounted for approximately $66 \%$ of the uronic acid content whereas hyaluronate accounted for nearly all the uronic acid in a sample of synovial fluid from a patient with systemic lupus erythematosus.

\section{CONCLUSIONS}

We believe the coupled enzyme-colorimetric assay described above will prove particularly suitable for the determination of hyaluronate in partially purified mixtures of glycosaminoglycans, and with proper precautions, in crude biological extracts. The methodology is sensitive, specific, and is not inhibited by the presence of other glycosaminoglycans.

\section{REFERENCES}

1. Mathews, M. B. (1966) in Methods in Enzymology (Neufeld, E. F., and Ginsburg, V., eds.), Vol. 8, pp. 654-662, Academic Press, New York.

2. Greiling, H. (1965) in Methods of Enzymatic Analysis (Bergmeyer, H. U., ed.), 2nd ed., pp. 87-92, Academic Press, New York.

3. Schiller, S., Slover, G. A., and Dorfman, A. (1961) J. Biol. Chem. 236, 983-987.

4. Antonopoulos, C. A., Gardell, S., Szirmai, J. A., and De Tyssonsk, E. R. (1964) Biochim. Biophys. Acta 83, 1- 19.
5. Svejcar, J., and Robertson, W. V. B. (1967) Anal. Biochem. 18, 333-350.

6. Breen, M., Weinstein, H. G., Andersen, M., and Veis, A. (1970) Anal. Biochem. 35, 146- 159.

7. Hardingham, T. E., and Adams, P. (1976) Biochem. J. 159, 143-147.

8. Linker, A., Meyer, K., and Hoffman, P. (1956) J. Biol. Chem. 219, 13-25.

9. Greiling, H., Günther, T., and Eberhard, T. (1960) Hoppe-Seyler's Z. Physiol. Chem. 319, $161-166$.

10. Reissig, J. L., Strominger, J. L., and Leloir, L. F. (1955) J. Biol. Chem. 217, 959-966.

11. Ohya, T., and Kaneko, Y. (1970) Biochim. Biophys. Acta 198, 607-609.

12. Hascall, V. C., Riolo, R. L., Hayward, J., Jr., and Reynolds, C. C. (1972) J. Biol. Chem. 247, $4521-4528$.

13. Koseki, M., Kimura, A., and Tsurumi, K. (1978) J. Biochem. 83, 553-558.

14. Warren, L. (1959) J. Biol. Chem. 234, 1971-1975.

15. Roseman, S., Watson, D. R., Duff, I. F., and Robinson, W. D. (1955) Fed. Proc. 14, 312.

16. Nagasawa, K., Inoue, Y., and Kamata, T. (1977) Carbohyd. Res. 58, 47-55.

17. Tolksdorf, S., McCready, M. H., McCullagh, D. R., and Schwenk, E. (1949) J. Lab. Clin. Med. 34, 74-89.

18. Aminoff, D. (1961) Biochem. J. 81, 384-392.

19. Waravdekar, V. S., and Saslaw, L. D. (1957) Biochim. Biophys. Acta 24, 439.

20. Bernheim, F., Bernheim, M. L. C., and Wilbur, K. M. (1948) J. Biol. Chem. 174, 257-264.

21. Bitter, T., and Muir, H. M. (1962) Anal. Biochem. 4, 330-334.

22. Horwitz, A. L., and Crystal, R. G. (1975) J. Clin. Invest. 56, 1312-1318. 